\title{
Formulation And Characterization Of Intra Nasal Delivery Of Nortriptyline Hydrochloride Thermoreversible Gelling System In Treatment Of Depression
}

\author{
Inayat Bashir Pathan ${ }^{{ }^{\star}}$, Baban More ${ }^{1}$ \\ 'Department of Pharmaceutics, Government College of Pharmacy, Aurangabad, India.
}

\begin{abstract}
The purpose of the present study is to develop a thermoreversible intra nasal gel of Nortriptyline hydrochloride (NTH). The prepared formulations were evaluated for gelation temperature, viscosity, gel strength, mucoadhesion strength, and drug content, ex vivo drug permeation, and stability study. The results found that as the concentration of poloxamer 188 and HPMC K4M were increased, there was increase in viscosity and mucoadhesive strength and decrease in gelation temperature and percent drug permeation. The optimized formulation F4 containing 3.6\% poloxamer and 0.04\% HPMC K4M showed highest drug release 98.25\% through sheep nasal mucosa. The intra nasal gel was stable for 3 months. It was concluded that, developed thermoreversible intra nasal formulations increased patient complain in treatment of a depression.
\end{abstract}

Keywords: Intra nasal gel, Nortriptyline hydrochloride, poloxamer

\section{INTRODUCTION}

Depression is a common psychiatric disorder affecting about 120 million people worldwide, and statistics clearly identify it as a major public health problem. ${ }^{1}$. Conventional oral dosage forms are available in market for treatment of depression, but the major drawbacks with these are many patients find it difficult to swallow (dysphagia) tablets and capsules. The difficulty experienced mainly in pediatrics and geriatrics patients ${ }^{2}$. The main advantages of nose to brain delivery such as rapidly absorbed through the nasal mucosa, preventing

${ }^{*}$ Corresponding author: Inayat Bashir Pathan

E-mail address: pathanpharma@gmail.com 
first pass metabolism and dodging of BBB. These nerve pathways initiate in the nasal cavity at olfactory neuroepithelium and terminate in the brain ${ }^{3-4}$. Both hydrophobic drugs, e.g. propranolol ${ }^{5}$ and hydrophilic drugs, e.g. vanlafaxine hydrochloride ${ }^{6}$ are absorbed by the nasal mucosa. Nortriptyline hydrochloride (NTH) is a tricyclic antidepressant widely used in the treatment of unipolar depression$^{7}$. Furthermore, it has been reported that up to $70 \%$ of patients who are prescribed oral antidepressants fail to take $25-50 \%$ of their prescribed dose ${ }^{8}$. Low oral bioavailability (30-50\%) and plasma level fluctuations such problems may cause lack of patient compliance and possible failure of the therapy ${ }^{9-8}$. Biodegradable, thermosensitive polymers have been extensively studied for their utility in formulation of thermoresponsive intranasal hydrogels ${ }^{10-11-12}$. In order to formulate thermosensitive intra nasal gel, thermoreversible polymer must have gelation temperature in the nasal physiological temperature range $\left(29^{\circ} \mathrm{C}\right.$ to $34^{\circ} \mathrm{C}$ ). Poloxamers are nonionic, poly(ethylene oxide)-poly(propylene oxide)poly(ethylene oxide) copolymers (PEO-PPO-PEO), which form micelles at low concentrations and clear thermoreversible gels at high concentrations ${ }^{13}$. Using hydrophilic excipients, gelation temperature of poloxamer blends can be modulated so that they form in-situ gels at body temperature ${ }^{14}$. Numbers of literature have reported the use of poloxamer gels in intranasal administration of drugs like anti-emetics ${ }^{15}$, anti-migraine agents ${ }^{16}$. Poloxamer 188 has low toxicity and biocompatibility, easy gel preparation methods, good compatibility with drugs and pharmaceutical excipients ${ }^{17-23}$. The objective of the present work was to develop a nose to brain delivery of Nortriptyline hydrochloride to enhanced patient compliance in treatment of depression.

\section{METHODOLOGY}

\section{Materials}

Nortriptyline Hydrochloride (NTH) was a gift sample from Swapnaroop drugs and chemicals, Aurangabad, India. Poloxamer-188 was procured as gift samples from BASF India Limited, Mumbai. HPMC K4M was a gift sample from Colorcon, Mumbai, India. Sodium metabisulpite and Benzalkonium chloride were obtained from Loba Chemie Pvt Ltd, Mumbai. DMSO was purchased from Vijay scientific Pvt Ltd. All other chemicals were of analytical reagent grade.

\section{Methods}

\section{Preparation of intra nasal gel}

The gel was prepared using the cold method ${ }^{24}$. The poloxamer-188 was slowly added and dissolved in cold water $\left(5^{\circ} \mathrm{C}\right)$ with continues stirring by mechanical stirrer (Remi motors Ltd, Mumbai, India, type RQ-122). The dispersion were 
then stored in refrigerator until clear solution was obtained. HPMC K4M with different concentration (0.04, 0.08 and $0.12 \%$ ) was dissolved in ultra-pure water and stirred for $60 \mathrm{~min}$. From the each prepared HPMC K4M solution NTH (0.2\% $\mathrm{w} / \mathrm{v}$ ) was added which was previously solubilized in co-solvent DMSO. Poloxamer 188 solution was added in HPMC solution containing drug with continuous stirring. Appropriate amount of benzalkonium chloride, sodium metabisulphite were added simultaneously. The prepared formulations are shown in Table 1.

Table 1: Formulations of Nortriptyline $\mathrm{HCl}$

\begin{tabular}{|l|l|l|l|l|l|l|l|l|l|}
\hline Ingredients & F1 & F2 & F3 & F4 & F5 & F6 & F7 & F8 & F9 \\
\hline Nortriptyline $\mathrm{HCl} \mathrm{( \% )}$ & 0.2 & 0.2 & 0.2 & 0.2 & 0.2 & 0.2 & 0.2 & 0.2 & 0.2 \\
\hline Ploxamer 188 (\%) & 3.4 & 3.4 & 3.4 & 3.6 & 3.6 & 3.6 & 3.8 & 3.8 & 3.8 \\
\hline HPMC K4M (\%) & 0.04 & 0.08 & 0.12 & 0.04 & 0.08 & 0.12 & 0.04 & 0.08 & 0.12 \\
\hline Benzalkonium chloride & 0.02 & 0.02 & 0.02 & 0.02 & 0.02 & 0.02 & 0.02 & 0.02 & 0.02 \\
\hline Sodium metabisulphite & 0.02 & 0.02 & 0.02 & 0.02 & 0.02 & 0.02 & 0.02 & 0.02 & 0.02 \\
\hline Ultra-pure water (q.s) ml & 100 & 100 & 100 & 100 & 100 & 100 & 100 & 100 & 100 \\
\hline
\end{tabular}

\section{Determination of gelation temperature}

Two milliliter aliquot of gel was transferred to a test tube, immersed in a water bath. The temperature of water bath was increased slowly at a constant rate of $1^{\circ} \mathrm{C}$ for $2 \mathrm{~min}$ from room temperature to the temperature at which gel formed. The sample was then examined for gelation, which was said to have occurred when the meniscus would no longer move upon tilting the test tube through an angle of $90^{\circ} 25$.

\section{Viscosity study}

The viscosity of intra nasal gel formulation before and after gelation was determined using Brookfield Rheometer R/S-CPS +1600 (Lauda Ecoline Staredition RE-204) $)^{26}$ having cone and plate geometry by using spindle coaxial CP75-1.

\section{Gel strength study}

Test was performed using a gel strength apparatus modified at the laboratory. Intra nasal gel formulation (50g) was placed in a $100 \mathrm{ml}-$ measuring cylinder and gelation was induced by simulated nasal fluid. The apparatus for measuring gel strength (weight: $35 \mathrm{~g}$ ) was then placed on the gel. The gel strength was measured by the minimal weight that pushed the apparatus $5 \mathrm{~cm}$ down through the gel ${ }^{27}$.

\section{Mucoadhesive strength study}

The fresh nasal mucosa was carefully removed from nasal cavity of sheep obtain from local slaughter house (Aurangabad). The nasal mucosa was mounted 
on glass surface using adhesive tape while another mucosal section was fixed in inverted position to the cylinder. $50 \mathrm{mg}$ of gel was placed on mucosal surface. The glass mounted mucosal surface with gel formulation and mucosal surface attached to cylinder were held in contact with each other for 2 min to ensure intimate contact between them. In second pan, the weights were increased until the two mucosal tissues got detached from each other. The nasal mucosa was changed for each measurement. The mucoadhesive force expressed as the detachment stress in dynes $/ \mathrm{cm}^{2}$ was determined from the minimal weight that detached the mucosal tissue from surface of each formulation ${ }^{28}$.

Mucoadhesive strength $\left(\right.$ dynes $\left./ \mathrm{cm}^{2}\right)=\mathrm{mg} / \mathrm{A}$

Where,

$\mathrm{m}=$ Weight required for detachment in gram,

$\mathrm{g}=$ Acceleration due to gravity $\left(980 \mathrm{~cm} / \mathrm{s}^{2}\right)$,

$\mathrm{A}=$ Area of mucosa exposed.

\section{Drug content}

The appropriate amount of formulation was taken and diluted with phosphate buffer pH6.6 and filter. The drug content was determined by using UV-visible spectrophotometer (Shimadzu, UV-1800, Lab India) at $\lambda_{\max } 239 \mathrm{~nm}$.

\section{Ex-vivo permeation study}

Institutional animal ethical committee approved the protocol (1211/PO/Re/ So8/CPCSEA). Ex-vivo permeation study of all formulations was carried out using Franz diffusion cell. Nasal mucosa was placed in diffusion cells displaying a permeation area of $0.785 \mathrm{~cm}^{2}$. The receiver compartment containing phosphate buffer pH 6.6 was maintained at $37 \pm 0.5^{\circ} \mathrm{C}$. After a pre-incubation time of 20 min, formulation equivalent to $20 \mathrm{mg}$ of NTH was placed in the donor chamber. At predetermined time points (30,60, 120, 180 and $240 \mathrm{~min}), 1 \mathrm{ml}$ of sample was withdrawn from the receptor compartment, replacing with fresh phosphate buffer $\mathrm{pH}$ 6.6 The samples withdrawn were filtered and amount of drug permeated was determined using UV-visible spectrophotometer (Shimadzu, UV-1800, Lab India) at $\lambda_{\max } 239 \mathrm{~nm}^{29}$.

\section{Release mechanism}

The Ex vivo permeation data were fitted to zero order, first order, Higuchi release model, Hixson and Crowell method and Korsemeyer-Peppas model by using DD Solver software, and the model with the higher correlation coefficient was considered to be the best model. 
The Korsemeyer-Peppas equation as follows:

$\mathrm{M}_{\mathrm{t}} / \mathrm{M}=\mathrm{Ktn}$

$\log \mathrm{Mt} / \mathrm{M}=\log \mathrm{K}+\mathrm{n} \log \mathrm{t}$

Where, $M_{t} / M=$ fraction of drug released at time $t, K=$ release rate constant, $n=i s$ the diffusion exponent indicating the release mechanism.

When $\mathrm{n}$ is equal to 0.5 , the drug release is with a fickian-diffusion mechanism (Higuchi model). If $0.5<\mathrm{n}>1$ this indicates anomalous or non-fickian release, while if $\mathrm{n}=1$ this indicates zero order release $\mathrm{e}^{30}$.

\section{Stability study}

The stability study was done on optimized formulation as per ICH guideline, at $40^{\circ} \mathrm{C} \pm 2^{\circ} \mathrm{C}$ and humidity $75 \% \mathrm{RH} \pm 5 \%$ condition in stability chamber (HMG, India) for three months. The formulation was examined for $\mathrm{pH}$, drug content and viscosity. ${ }^{31}$

\section{RESULTS AND DISCUSSION}

\section{Gelation temperature study}

All the formulation showed gelation temperature between $32 \pm 1.0^{\circ} \mathrm{C}$ to $34 \pm$ $1.0^{\circ} \mathrm{C}$. From results, it revealed that concentration of poloxamer 188 increased, the gelation temperature decreased shown in table 2 . This can be explained by one of the proposed mechanism of gelation of aqueous poloxamer solutions, packaging of micelles and micelle entanglements have been suggested. With increasing temperature, micellization becomes more important and then at a definite point micelles come into contact and no longer move ${ }^{10}$ therefore, if the poloxamer concentration in an aqueous solution is higher, packaging of micelles will occur at lower temperatures. As the concentration of poloxamer 188 increases, the gel structure becomes more closely packed with the arrangement in the lattice pattern and gelling occurs rapidly at low temperature. From above results obtained, gelation temperature study of all formulations, it was seen that all formulation showed gel formation at nasal physiological temperature i.e $32^{\circ} \mathrm{C}$ to $35^{\circ} \mathrm{C}$ as reported ${ }^{32}$.

\section{Viscosity study}

Viscosity of all formulation before and after gel formation shown in Table 2. From results it found that the concentration of HPMC increased (0.04-0.12\%), the viscosity increased. Similarly the concentration of poloxamer increased (3.4$3.8 \%$ ), the viscosity increased. This effect could be attributed to the increase in the number and size of the micelles formed at the higher polymer concentration. 
Furthermore, higher polymer concentration could result in a shorter intermicellar distance, leading to greater number of cross-links between neighboring micelles and a greater number of micelles per unit volume ${ }^{33}$. The viscosity of both, solution and gel formulations, was found to be proportionate to the increase in polymer concentration.

\section{Gel strength}

The gel strength values between 25-50 sec are considered adequate. The gel strength less than $25 \mathrm{sec}$ may not retain its integrity and may erode rapidly while gel having strength greater than $50 \mathrm{sec}$ is too stiff and may cause discomfort to the mucosal surfaces. Formulations (F1-F9) had gel strength between 28.2 sec to $51.83 \mathrm{sec}$ in triplicate as shown in Table 2 and were considered suitable for nasal administration.

\section{Mucoadhesive strength study}

Our study indicates that, the concentration of HPMC increases the mucoadhesive strength goes on increasing shown in Table 2. HPMC is a hydrophilic polymer with many polar functional groups. Upon hydration the polymeric chains of HPMC get entangled with glycoprotein chains of mucin resulting in bioadhesion 34-35. The significant effect was observed with HPMC as compared to poloxamer. This was due to wetting and swelling of HPMC, which permits intimate contact with nasal tissue, interpenetration of mucoadhesive HPMC chains with mucin molecules leading to entanglement and formation of weak chemical bonds between entangled chains. Due to stronger mucoadhesive force, it can prevent the

gelled solution coming out of the nose and increases its residence time in nasal cavity. The degree of bioadhesion depends on type and amount of polymer, excipients used in the dosage form, degree of hydration, polymer chain length and molecular weight of polymer ${ }^{36-37}$.

\section{Drug content}

The percent drug content of all formulations was found to be in the range, 98.35101.71\% shown in table 2, which revealed that drug is uniformly distributed within formulation.

\section{Ex vivo permeation studies}

Ex vivo permeation profile of all formulations was studied using sheep nasal mucosa. The results show that as the level of poloxamer was increased (3.4 to $3.8 \%$ ), the drug release was decreased. These results indicated that the concentration of polymer increased, structure of the gel became more closely packed and functioned as an increasingly resistant barrier to drug release. The percent- 
age drug permeated after 240 min of all formulations was found to be between 75.50 to $98.25 \%$ (Figure 1). As compared to all formulation F4 (98.25\%) showed highest drug release and considered as optimized formulation for further stability study. The initial rates of permeation were very rapid due to incomplete gel formation, but as the time progresses the permeation rate decreases due to complete gel formation. With an increase in concentration of HPMC (0.04 to $0.12 \%)$, the diffusion rates were found to decrease gradually. An increase in polymer concentration increases the viscosity of gel layer with longer diffusional path length resulting in greater retardation of drug in gel. The permeation profiles exhibited an inflection point, which indicated the gel formation in the donor compartment of diffusion cell. During gel formation, a portion of drug might be loaded into the gel matrix, thus the cross-linking of polymer reduces the drug permeation rate.

Table 2: Gelation temperature, viscosity, gel strength and mucoadhesive strength and drug content

\begin{tabular}{|c|c|c|c|c|c|c|c|}
\hline \multirow{2}{*}{ 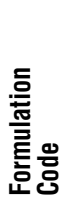 } & \multirow{2}{*}{ 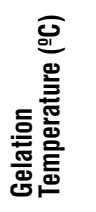 } & \multicolumn{2}{|c|}{ Viscosity (cp) } & \multirow{2}{*}{ 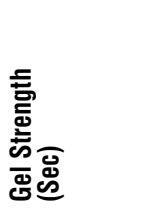 } & \multirow{2}{*}{ 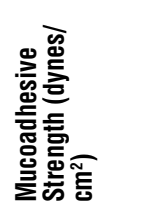 } & \multirow{2}{*}{ 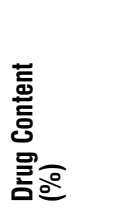 } & \multirow{2}{*}{ 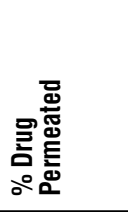 } \\
\hline & & Sol & Gel & & & & \\
\hline $\mathrm{F} 1$ & $34 \pm 1.0$ & $33.16 \pm 0.3$ & $451.16 \pm 0.76$ & $28 \pm 2$ & $1784.46 \pm 1.2$ & $99.25 \pm 0.12$ & $81.53 \pm 2.2$ \\
\hline F2 & $34 \pm 1.0$ & $39.06 \pm 0.6$ & $553.5 \pm 1.04$ & $32.66 \pm 2.08$ & $1994.70 \pm 1.2$ & $101.71 \pm 0.2$ & $73.52 \pm 4.6$ \\
\hline F3 & $34 \pm 1.0$ & $47.80 \pm 0.3$ & $677.4 \pm 0.6$ & $36.5 \pm 0.25$ & $2195.54 \pm 2.1$ & $98.35 \pm 0.9$ & $70.02 \pm 5.8$ \\
\hline F4 & $33 \pm 1.0$ & $54.35 \pm 0.2$ & $751.83 \pm 1.60$ & $37.3 \pm 0.51$ & $2450.69 \pm 2.40$ & $99.81 \pm 0.4$ & $98.25 \pm 2.6$ \\
\hline F5 & $33 \pm 1.0$ & $63.67 \pm 0.5$ & $842.6 \pm 0.52$ & $42.13 \pm 0.41$ & $2557.49 \pm 2.16$ & $98.62 \pm 0.5$ & $91.48 \pm 5.4$ \\
\hline F6 & $33 \pm 1.0$ & $72.31 \pm 0.5$ & $850 \pm 1$ & $44.66 \pm 0.70$ & $2359.54 \pm 3.3$ & $99.21 \pm 0.7$ & $82.22 \pm 4.4$ \\
\hline F7 & $32 \pm 1.0$ & $82.75 \pm 0.3$ & $985.2 \pm 0.8$ & $38.73 \pm 0.25$ & $2670.2 \pm 4.3$ & $98.91 \pm 0.8$ & $84.28 \pm 5.5$ \\
\hline F8 & $32 \pm 1.0$ & $97.26 \pm 0.3$ & $1004.5 \pm 2.23$ & $46.6 \pm 0.52$ & $2746.05 \pm 5.7$ & $99.25 \pm 0.3$ & $81.22 \pm 3.8$ \\
\hline F9 & $32 \pm 1.0$ & $107.60 \pm 0.8$ & $1011.5 \pm 2.17$ & $51.83 \pm 0.73$ & $2785.79 \pm 5.4$ & $99.1 \pm 0.2$ & $75.50 \pm 4.7$ \\
\hline
\end{tabular}

\section{Release mechanism}

The results obtained from release kinetics it could be concluded that, the formulations ( $\mathrm{F} 1$ to $\mathrm{F} 9$ ) exhibited $\mathrm{n}$ values between 0.548 - 0.976 indicating an anomalous or nonfickian release suggesting a coupled erosion- diffusion mechanism.

\section{Stability study}

In stability study, there was no significant change found in drug content, $\mathrm{pH}$ and viscosity as shown in Table.3. From above results, it was concluded that prepared formulation is stable. 


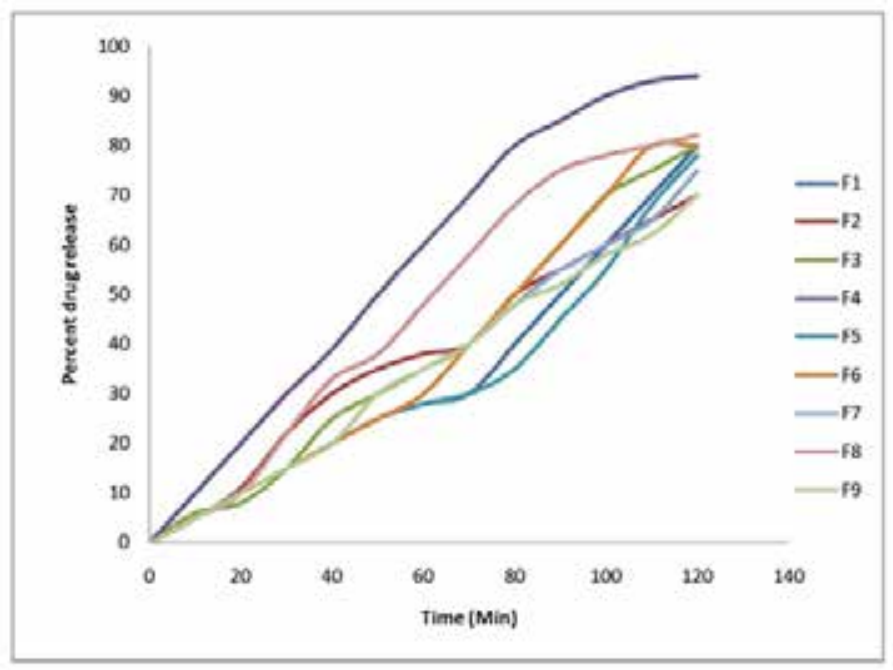

Figure 1: Ex vivo permeation profile of all formulations through sheep nasal mucosa

Table 3: Stability results of optimized F4 formulation

\begin{tabular}{|l|l|l|l|}
\hline Days & Drug content (\%) & $\mathbf{p H}$ & Viscosity (cp) \\
\hline 0 & $99.81 \pm 0.4$ & $5.65 \pm 0.02$ & $54.35 \pm 0.24$ \\
\hline 30 & $99.34 \pm 0.11$ & $5.66 \pm 0.06$ & $56.12 \pm 0.09$ \\
\hline 60 & $99.03 \pm 0.06$ & $5.68 \pm 0.09$ & $57.39 \pm 0.17$ \\
\hline 90 & $98.95 \pm 0.13$ & $5.78 \pm 0.15$ & $58.60 \pm 0.11$ \\
\hline
\end{tabular}

\section{CONCLUSION}

The optimized formulation $\mathrm{F}_{4}$ containing $3.6 \%$ poloxamer 188 and $0.04 \%$ HPMC K4M show highest drug release 98.25 \% through sheep nasal mucosa. It was concluded that, the intra nasal formulations of Nortriptyline hydrochloride (NTH) was effectively formulated to enhanced patients compliance for the treatment of depression.

\section{REFERENCES:}

1. Tortora, G. J.; Derrickson, B. Principles of Anatomy and Physiology; 2014.

2. Brunton, L. Goodman \& Gilman 's The Pharmacological Basis of Therapeutics; 2006.

3. Pardeshi, C. V.; Belgamwar, V. S. Direct nose to brain drug delivery via integrated nerve pathways bypassing the blood-brain barrier: an excellent platform for brain targeting. Expert Opin. Drug Deliv. 2013, 10 (7), 957-972.

4. Astic, L.; Saucier, D.; Coulon, P.; Lafay, F.; Flamand, A. The CVS strain of rabies virus as transneuronal tracer in the olfactory system of mice. Brain Res. 1993, 619 (1-2), 146-156.

5. Hussain, A.; Foster, T.; Hirai, S.; Kashihara, T.; Batenhorst, R.; Jones, M. Nasal absorption of propranolol in humans. Sect. Title Pharmacodyn. 1980, 69 (10), 1240. 
6. Pathan, I. B.; Nirkhe, S. R.; Bairagi, A. In situ gel based on gellan gum as new carrier for nasal to brain delivery of venlafaxine hydrochloride: In vitro evaluation and in vivo study. $J$. Chem. Pharm. Res. 2015, 7 (9), 324-331.

7. Hughes, J. R. Mechanism of action of a decision aid for smoking cessation treatment. Addiction. 2006, 101 (9), 1362.

8. Stimmel, G. L. Benzodiazepines in schizophrenia. Pharmacotherapy 1996, 16 (0277-00o8 (Print)), 148S-151S.

9. Prochazka, A.V.; Weaver, M. J.; Keller, R. T.; Fryer, G. E.; Licari, P. A; Lofaso, D. A Randomized Trial of Nortriptyline for Smoking Cessation. Arch. Intern. Med. 1998, 158 (18), 2035-2039.

10. Ruel-Gariépy, E.; Leroux, J. C. In situ-forming hydrogels-review of temperature-sensitive systems. Eur. J. Pharm. Biopharm. 2004, pp 409-426.

11. Nazar, H.; Fatouros, D. G.; Van Der Merwe, S. M.; Bouropoulos, N.; Avgouropoulos, G.; Tsibouklis, J.; Roldo, M. Thermosensitive hydrogels for nasal drug delivery: the formulation and characterisation of systems based on N-trimethyl chitosan chloride. Eur. J. Pharm. Biopharm. 2011, 77 (2), 225-232.

12. Cai, B. L.; Chang, Y. G.; Mei, J. H.; Ji, W. W.; Yi, F. P.; Yang, D. Z.; Guo, Z. L.; Ma, L. G.; Wang, K.; Ming, J. T.; Yu, Q. W.; Qian, Z. Y. Thermoreversible gel-sol behavior of biodegradable PCL-PEG-PCL triblock copolymer in aqueous solutions. J. Biomed. Mater. Res.-Part B Appl. Biomater. 2008, 84 (1), 165-175.

13. Matanović, M. R.; Grabnar, P. A.; Voinovich, D.; Golob, S.; Mijovski, M. B.; Grabnar, I. Development and preclinical pharmacokinetics of a novel subcutaneous thermoresponsive system for prolonged delivery of heparin. Int. J. Pharm. 2015, 496 (2), 583-592.

14. Zhou, M.; Donovan, M. D. Intranasal mucociliary clearance of putative bioadhesive polymer gels. Int. J. Pharm. 1996, 135 (1-2), 115-125.

15. Zaki, N. M.; Awad, G. A.; Mortada, N. D.; Abd ElHady, S. S. Enhanced bioavailability of metoclopramide $\mathrm{HCl}$ by intranasal administration of a mucoadhesive in situ gel with modulated rheological and mucociliary transport properties. Eur. J. Pharm. Sci. 2007, 32 (4-5), 296-307.

16. Majithiya, R. J.; Ghosh, P. K.; Umrethia, M. L.; Murthy, R. S. R. Thermoreversible-mucoadhesive gel for nasal delivery of sumatriptan. AAPS PharmSciTech 2006, 7 (3), 67.

17. Barichello, J. M.; Morishita, M.; Takayama, K.; Nagai, T. Absorption of insulin from pluronic F-127 gels following subcutaneous administration in rats. Int. J. Pharm. 1999, 184 (2), 189-198.

18. Cafaggi, S.; Russo, E.; Caviglioli, G.; Parodi, B.; Stefani, R.; Sillo, G.; Leardi, R.; Bignardi, G. Poloxamer 407 as a solubilising agent for tolfenamic acid and as a base for a gel formulation. Eur. J. Pharm. Sci. 2008, 35 (1-2), 19-29.

19. Dalmoro, A.; Barba, A. A.; Lamberti, G.; Grassi, M.; D’Amore, M. Pharmaceutical applications of biocompatible polymer blends containing sodium alginate. Adv. Polym. Technol. 2012, 31 (3), 219-230.

20. Grassi, G.; Farra, R.; Noro, E.; Voinovich, D.; Lapasin, R.; Dapas, B.; Alpar, O.; Zennaro, C.; Carraro, M.; Giansante, C.; Guarnieri, G.; Pascotto, A.; Rehimers, B.; Grassi, M. Characterization of nucleic acid molecule/liposome complexes and rheological effects on pluronic/alginate matrices. J. Drug Deliv. Sci. Technol. 2007, 17 (5), 325-331.

21. Sharma, P. K.; Bhatia, S. R. Effect of anti-inflammatories on Pluronic F127: micellar assembly, gelation and partitioning. Int. J. Pharm. 2004, 278 (2), 361-377. 
22. Ur-Rehman, T.; Tavelin, S.; Gröbner, G. Chitosan in situ gelation for improved drug loading and retention in poloxamer 407 gels. Int. J. Pharm. 2011, 409 (1-2), 19-29.

23. Xuan, J. J.; Balakrishnan, P.; Oh, D. H.; Yeo, W. H.; Park, S. M.; Yong, C. S.; Choi, H. G. Rheological characterization and in vivo evaluation of thermosensitive poloxamer-based hydrogel for intramuscular injection of piroxicam. Int. J. Pharm. 2010, 395 (1-2), 317-323.

24. Schmolka, I. R. Artificial skin. I. Preparation and properties of pluronic F-127 gels for treatment of burns. J. Biomed. Mater. Res. 1972, 6 (6), 571-582.

25. Choi, H. G.; Oh, Y. K.; Kim, C. K. In-situ gelling and mucoadhesive liquid suppository containing acetaminophen: enhanced bioavailability. Int. J. Pharm. 1998, 165 (1), 23-32.

26. Chang, J. Y.; Oh, Y. K.; Choi, H. gon; Kim, Y. B.; Kim, C. K. Rheological evaluation of thermosensitive and mucoadhesive vaginal gels in physiological conditions. Int. J. Pharm. 2002, 241 (1), 155-163.

27. Kim, C. K.; Lee, S. W.; Choi, H. G.; Lee, M. K.; Gao, Z. G.; Kim, I. S.; Park, K. M. Trials of in-situ gelling and mucoadhesive acetaminophen liquid suppository in human subjects. Int. $J$. Pharm. 1998, 174 (1-2), 201-207.

28. Bansal, K.; Rawat, M. K.; Jain, A; Rajput, A; Chaturvedi, T. P.; Singh, S. Development of Satranidazole Mucoadhesive Gel for the Treatment of Periodontitis. AAPS PharmSciTech 2009, 10 (3), 716-723.

29. Naik, A.; Nair, H. Formulation and evaluation of thermosensitive biogels for nose to brain delivery of doxepin. Biomed Res. Int. 2014, 2014.

30. Korsmeyer, R. W.; Gurny, R.; Doelker, E.; Buri, P.; Peppas, N. A. Mechanisms of solute release from porous hydrophilic polymers. Int. J. Pharm. 1983, 15 (1), 25-35.

31. Ali, M. S.; Alam, M. S.; Alam, N.; Anwer, T.; Safhi, M. M. A. Accelerated Stability Testing of a Clobetasol Propionate-Loaded Nanoemulsion as per ICH Guidelines. Sci. Pharm. 2013, 81 (4), 1089-1100.

32. Mygind, N.; Dahl, R. Anatomy, physiology and function of the nasal cavities in health and disease. Adv. Drug Deliv. Rev. 1998, 29 (1-2), 3-12.

33. Zhang, L.; Parsons, D. L.; Navarre, C.; Kompella, U. B. Development and in-vitro evaluation of sustained release poloxamer 407 ( $\mathrm{P} 407$ ) gel formulations of ceftiofur. J. Control. Release 2002, $85(1-3), 73-81$.

34. Andrews, G. P.; Laverty, T. P.; Jones, D. S. Mucoadhesive polymeric platforms for controlled drug delivery. Eur. J. Pharm. Biopharm. 2009, 71 (3), 505-518.

35. Jaipal, A.; Pandey, M. M.; Abhishek, A.; Vinay, S.; Charde, S. Y. Interaction of calcium sulfate with xanthan gum: Effect on in vitro bioadhesion and drug release behavior from xanthan gum based buccal discs of buspirone. Colloids Surf. B Biointerfaces 2013, 111, 644-650.

36. Charde, S.; Mudgal, M.; Kumar, L.; Saha, R. Development and Evaluation of Buccoadhesive Controlled Release Tablets of Lercanidipine. AAPS PharmSciTech 2008, 9 (1), 182-190.

37. Salamat-Miller, N.; Chittchang, M.; Johnston, T. P. The use of mucoadhesive polymers in buccal drug delivery. Adv. Drug Deliv. Rev. 2005, 57(11), 1666-1691.

(Received o6 February 2017; accepted o3 March 2017) 